\title{
Topografisk Ordning af Sønderjyllands Egne.
}

(Til Brug ved studium af Senderjyllands Almueknitur

og Folkominder).

Ved August F. Schmidt.

I Da nsk Folke mindes a m l i ng, Kgl. Bibliotek, København $K$,, er Hovedparten af det omfattende sønderjydske Folkemindestof (se Sønderjydske Årbøger 1930, s. 41-49), som der findes opbevaret for kommende Slagter, ordnet t o p o g r a f is k, d. v. s. ef t e r Sog ne. Herunder hører, hvad der af Folkeminder let lader sig stedfeste: Sagn, Tro, Fester, Folkeliv, Billeder m. v. Hvert Sogn i Danmark har til Brug for Ordningen af Dansk Folkemindesamlings Materiale sit bestemte Topografinumner. Samme Nummersystem bruges også i $S$ tedn a v n e dvalget. Sognenes Rakkefolge i Dansk Folkemindesamlings Arkiv af danske Folkeminder er den, som forefindes i tredje Udgave af Traps Danmark og for Sønderjyllands Vedkommende Sognefølgen i Traps Bind om Hertugdømmet Slesvig (1864). Det givne Sognenummer skrives pá hvert Blad Optegnelser, som hidrører fra det respektive Sogn. Iet er derfor let at finde frem af det valdige Folkemindemateriale, hvad der soges fra en hvilken som helst Egn af Landet lige til Ejderen, nàr blot man har et eller flere Sognenavne. Stoffet er nemlig nøje ordnet efter de givne topografiske Lobenunme fra 1 til 3473. Disse Numre er - med Undtagelse af Landet Syd for den nu slettede Kongeågranse - trykte i Fests k rift til H. F. F e i l b e r g 1911, s. $4 \%$-88.

Da det vil viele praktisk ogsả at have trykt den topografiske Fortegnelse over Landet mellem Kongeåen og Fjderen, skal den derfor her offentliggøres efter Dansk Folkemindesamlings hidtil utrykte "Sønderjyllands Topografi«, der som næevnt til Forudsatning har Sognefølgen i Traps Sonderjyllandsbind fra 1864. Sognene i Landet mellem Kongeågransen og Ejderen har deres Numle i Mellemrummet 3000 3473. Med den topografiske Fortegnelse ved Hånden kan enhver, (ler beskæftiger sig med sศnderjydsk Lokalhistorie, Alnuekultur, Folketro o. s. v. finde Numret på det Sogn, der har sarlig Interesse. Med Angivelse af 
Topografinumret og Sognenavnet kan vedkommende $f$. Eks. ved en skriftlig Henvendelse til Dansk Folkemindesamling få tilsendt Oplysninger om, hvad der eventuelt findes fra Sognet i Samlingens forskellige utrykte Rækker af Folkeminder. Eksisterer der Optegnelser fra det pågroldende Sogn, kan disse erholdes mod en lille Timebetaling i Afskrivningspenge. Er det sidant, at man on. sker at gennemgá alle Optegnelser fra Sønderjylland af en bestemt Skik, en Trosforestilling, en speciel Sagngruppe et. lign., er dette Stof let at finde frem, dels pả Grund af det topografiske Nummersystem, dels fordi der findes Afskriftsrækker af eller Henvisninger til sådant særrligt karakteristisk Folkemindemateriale. Hoveds a mlingen af danske Folkeminder, indsendt til Dansk Folkemindesamling siden 1906, findes i Arkivrækkerne 1906/23 til 1906 92. Her er alle Originaloptegnelserne, Avisudklip, Afskrifter og Henvisninger. Søger en Forsker Oplysninger f. Eks. om Hekse og kloge Folk i Sønderjyllanf, da findes disse hurtigere i Udtogs- og Afskriftsrakken 1906/28 III, Top. 3000 ff., end i Originalrækkerne $1906 / 23 \mathrm{~m}$. v., hvor der jo også findes meget andet Stof. (Jnsker man at se Optegnelserne om Fester i Sønderjylland, kan man foruclen Originaloptegnelserne i 1906/43 gennemgả Udklipsog Afskliviningsrakkorne 190644 A-I 1906/45 A-I osv. (se nermere Festskrift til H. F. Feilberg 1911, S. 475).

Foruden i Rakkerne 1906/23 - 1906,92 findes der også sonderjydske Folkeminder i H. F. Feilbergs Samli ng, f. Eks. M. J. Skovs Optegnelser fra (Oster Abollingegnen (1922/71), i A xel Ol ri ks Samling, E vald Tang Kristensens Samling og i Hans Pilegaards to Kapsler. Disse Samlingers sønderjydske Folkeminder $\mathrm{m}$. v. er man selvsagt også nødt til at gennemgå, hvis man onsker at kende hele Dansk Folkemindesamlings sonderjydske Stof (jfr. Sdj. Årb. 1930, 43-48).

I den topografiske Ordning af Sønderjyllands Egne er hvert Sogn, Herred, Amt eller Landskab forsynet med eget Nummer. Herredets Nummer ender altid på 0 . I det f $($ lgende meddeles Ordningen sta:rkt sammentrængt; $f$. Eks.: 3080 Hviding Iferred, 3081 Arrild sogn, 3082 Højrup Sogn, 3083 Spandet Sogn, er trykt som 3080 Hviding, 81 Arrild, 82 Højrup, 83 Spandet.

3000 Sønderjylland.

:3001 II a ders lev 9 s t e r a m t, 02 Haderslev. $3010 \mathrm{Ha}$ dersiev: 11 GI. IIaderslev, 12 Hoptrup, 13 Vil- 
strup, 14 Starup, 15 Grarup, 16 Ilalk, 17 Osby. 18 Vonsbæk, 19 Astrup, 21 Moltrup, 22 Bjærning.

3030 S.-T y r s tru p: 31 Fjelstrup, 32 Aller, 33 Tyrstrup, 34 Christiansfeld, 35 Hjerndrup, 36 Frorup, 37 Stepping.

3040 G r a m: 41 Sommersted, 42 Oksenvad, 43 Jegerup, 44 Magstrup, 45 Hammelev, 46 Vedsted, 47 Skrydstrup, 48 Nustrup.

$3049 \mathrm{H}$ a derslev Vestera mit.

$3050 \mathrm{~F} \mathrm{røs} \mathrm{og} \mathrm{Ka} \mathrm{I} \mathrm{v} \mathrm{I} \mathrm{u} \mathrm{nd:} 51$ Øster Lindet, 52 Jels, 53 Skodborg, 54 Skrave, 55 Rødding, 56 Hjerting, 57 Lintrup, 58 Hygum, 59 Fole, 61 Gram.

3070 Nørre Rangstrup: 71 Toftlund, 72 Tislund, 73 Bevtoft, 74 Agerskov, 75 Branderup.

$3080 \mathrm{Hviding:} 81$ Arrild, 82 Højrup, 83 Spandet, 84 Roager, 85 Hviding, 86 Rejsby, 87 Brans, 88 Vodder, 89 Skærbæk.

3091 Tønder Nørream t, 92 Tønder.

$3100 \mathrm{~T} ø \mathrm{nde} \mathbf{r}$ o g $\mathrm{H}$ øjer: 01 Tønder Landsogn, 02 Møgeltønder, 03 Højer, 04 Højer Landsogn, 05 Daler, 06 Visby, 07 Emmerlev, 08 Hjerpsted, 09 Skast, 11 Ballum, 12 Rømø, 13 Randerup, 14 Mjolden, 15 Døstrup, 16 Brede, 17 Nørre-Løgum, 18 Løgumkloster, 19 Løgumkloster Landsogn, 21 Abild, 22 Ubjarg.

3130 Slog s: 31 Hostrup, 32 Hujst, 33 Rabsted, 34 Bylderup, 35 Burkal, 36 Tinglev.

$3137 \mathrm{~T} ø \mathrm{nder} \mathrm{S} ø \mathrm{nderam} \mathrm{t}$ (Nordfrisland).

$3140 \mathrm{~K}$ æ : 41 Medelby, 42 Ladelund, 43 Sønder Løgum, 44 Humtrup, 45 Brarup, 46 Karlum, 47 Klægsbal, 48 Læk, 49 Enge, 51 Stedesand, 52 "Marsken«.

3160 Viding: 61 Aventoft, 62 Nykirke, 63 Rødenæs, 64 Klangsbøl, 65 Horsbøl, 66 Embsb $ø l$.

$3170 \mathrm{~B} \otimes \mathrm{k}$ in g: 71 Nibøl, 72 Desbøl, 73 Lindholm, 74 Risum, 75 Dagebøl, 76 Foretoft, 77 Galmsbø்l.

3178 S ild: 79 Sild Vesterland, 81 Sild Morsum, 82 Sild Kejtum.

3183 Før: 84 Før Wyk, 85 Før St. Nikolai, 86 Før St. Johannes, 87 Før St. Laurentii.

3188 A m rum. 
3189 A b e n r à A m t, 91 Abenrả By og Landsogn.

3200 S g n d e r - Rang a t ru p Herred: 01 Bedsted, 02 Hellevad, 03 Egvad, 04 Øster Løgum.

$3210 \mathrm{R}$ is e: 11 Løjt, 12 Rise, 13 Hjordkær, 14 Bjolderup.

3220 L u n d t of t: 21 Uge, 22 Kliplev, 23 Ensted, 24 Felsted, 25 Varnæs, 26 Asbøl, 27 Gråsten, 28 Kværs, 29 Rinkenees, 31 Holbøl.

$3232 \mathrm{~S}$ ø $\mathrm{nder}$ b org A $\mathrm{m} \mathrm{t}, 33$ Sønderborg.

3240 N y bø I Herred (Sundeved), 41 Dybbøl, 42 Sottrup, 43 Ullerup, 44 Nybøl, 45 Broager.

3246 A $1 \mathrm{~s}$.

$3250 \mathrm{~S}$ nd e r H e r red: 51 Kegnæs, 52 Lysabild, 53 Tandslet, 54 Hørup, 55 Ulkebøl, 56 Augustenborg, 57 Ketting, 58 Asserballe, 59 Notmark.

3260 Nør r H e r red: 61 Egen, 62 Svenstrup, 63 Hagenbjærg, 64 Oksbøl, 65 Nordborg Flække, 66 Nordborg Landsogn.

$3 \overline{2} 67$ F 1 e n s b o r g.

3268 F len s borg A m t.

3270 V i s: 71 Bov, 72 Hanved; 73 Valsbøl, 74 N. Haksted, $75 \mathrm{St}$. Vi, 76 Vandrup.

3280 Ug l e: 81 Oversø, 82 Jørl, 83 Eggebæk, 84 Siversted, 85 Store Solt, 86 Lille Solt.

3287 A n g e l.

$3290 \mathrm{H} \mathrm{u} \mathrm{s} \mathrm{by,} \mathrm{M.u} \mathrm{nkbra} \mathrm{r} \mathrm{u} \mathrm{p:} 91$ Hyrup, 92 Adelby, 93 Rylskov, 94 Munkbrarup, 95 Lyksborg, 96 Grumtoft, 97 Husby.

3300 N y: 01 Sørup, 02 Kværn, 03 Nykirke, 04 Stenbjærg, 05 Sterup, 06 Eskris, 07 Gelting.

3308 G o t t o r p A m t (Sydslesvig).

3309 Slesvig med Gottorp.

$3310 \mathrm{~S}$ l is $0 \mathrm{~g}$ F y s in g: 11 Brodersby, 12 Torsted, 13 Ulsnæs, 14 Løjt, 15 S. Brarup, 16 Borne, 17 Ravnkær, 18 Arnæs, 19 Kappel, 21 Kappel Landsogn.

3330 S t r u k tru p, Mák æ r og Så t r u p: 31 Tøstrup, 32 N. Brarup, 33 Bøl, 34 Sảtrup, 35 Havetoft, 36 Ølsby, 37 Tumby, 38 Strukstrup, 39 N. Farensted, 41 Tolk, 42 Nybøl, 43 Kaleby, 44 Moldened, 45 Slesvig St. Michaelis Landsogn. 
3350 Tr j ja, A r n s og Bollingsted: 51 Treja, $5 \dot{2}$ flollingsted, 53 Haddeby (med Danevirke).

$3360 \mathrm{Kropp}$ og Meggerdorf, Stapelholm: 61 Kropp, 62 Bergenhusen, 63 Erfde, 64 Süderstapel, 65 Frederiksstad.

3366 H u s u A m t (og B redsted A m t), 67 Húsum.

$3368 \mathrm{~F} r$ is l a nd.

$3370 \mathrm{~N}$ ør e Gos Herred (Bredsted): 71 Fjolde, 72 Hjoldelund, 73 Bjerrum, 74 Langhorn, 75 Okholm, 76 Bordelum, 77 Bredsted By, 78 Bredsted Landsogn, 79 Breklum, 81 Drelsdorf.

$3390 \mathrm{H}$ u s u m Nørre og Sønder Herred: 91 Olderup, 92 Svesing, 93 Ilatsted, 94 Skobøl, 95 Simonsberg, 96 Mildsted, 97 Ostenfeld, 98 Svavsted, 99 (Halligerne), 3401 Oland, 02 Grøde, 03 Langenæs, 04 Hoge, 05 Gen Pelvorm (06 Gammelkirke, 07 Nykirke).

3408 o en Nordstrand (Odenbüll) (m. Nordstrandisch mohr).

3409 E j d e r s te d A m t („Ejdersted «).

3411 Tønning By, 12 Tønning Landsogn, 13 kotzenbüll, 14 kating, 15 Vollerwiek, 16 Welt, 17 Garding, 18 Garding Landsogn, 19 Tating, 21 St. Peter, 22 Ording, 23 W.-Hever, 24 Ø-Hever, 25 Poppenbüll, $26 \mathrm{Te}$ tenbüll, 27 Katharinenheerd, 28 Oldenswort, 29 tivesbüll, 31 Witzwort, 32 Koldenbüttel.

3433 Eck er $n$ f б rde (og H ü t te n) A $\mathrm{m} \mathrm{t}, 34$ Eckernførde. 3440 F ckernforde Herred: 41 Eckernførde Landsogn, 42 Borreby, 43 Kosel, 44 (S v a n s), 45 Riseby, 46 Siseby, 47 Svans, 48 Vabs, - 49 (D ä n i s c h wo h 1 d), 51 Krusendorf, 52 Dänischenhagen, 53 Holtenau, 54 Gettorf, 55 Sehestedt.

$3460 \mathrm{H}$ ü t t e n H e r red: 61 Bünsdorf. 62 Hütten.

$3463 \mathrm{Rens}$ borg A m t.

3470 Hohn Herred: 71 Hohn, 72 IIamdorf, 73 Rensborg Kristkirke.

I den nye Udgave af Traps Danmark, hvor de sønderjydske Landsdele er beskrevne i Bind IX (1925-29), er Sognenes Rækkefølge på Grund af administrative - Fndringer $i$ de fleste Herreder af Nordslesvig noget afvigende fra 
Rækkefølgen i Traps første Udgave fra 1864. Det vil være rimeligt her at meddele disse Afvigelser, der i nogle Tilfælde også gælder Herreder og Købstæder.

Herredsfolgen:

H a d e r s lev A m t: S. Tyrstrup, Haderslev, Gram, Fros, N. Rangstrup.

T ø n d e r A m t: Hviding, Tønder, Højer og Lø, Slogs.

A b e $\mathrm{n}$ ra A $\mathrm{m}$ t: $\mathrm{S}$. Rangstrup, Rise, Lundtoft og Vis.

Sonde rborg A m t: Nybøl, Als Sdr,- Als Nr, H.

Sognefolgen:

Sonder - T y r s tu u p Herred: $3032,33,35,31,22,37$

(Christiansfeld 34 står bagefter Haderslev 3002).

II a d e r s l e v Herred: 3011, 12, 13, 14, 15, 16, 17, 18, 19, 21. G r a m H e rred: 3042, 52, 41, 44, 43, 45, 46, 48, 47 .

F r ø s Herred: $3051,55,54,53,58,57,56,61,59$.

Norre Rang s trup Herred: $3071,75,74,73,72$.

H v id ing Herred: $3085,86,84,83,82,88,87,89,81$.

Tønd e r, Hø j e r og $L ø$ Herreder, der skildres i Sammenhang: $3101,22,02,04,05,06,07,08,11,12,14,13$, 09, 16, 17, 19, 21. - Højer (3103) og Løgumkloster (3118) følger i Trap IX efter Tønder 3092.

Slogs, Sønder - Rangstrup og R is e Herreder har samme Sognefølge i Trap 1864 og Trap 1925-29.

L u n d t o f t - V i s Herreder: $3221,23,24,25,26,27,29,28$, $22,31,71$.

N y b o l Herred: ingen Forskel.

A ls. Augustenborg og Nordborg (3256, 3265) følger efter Sønderborg 3233.

A I s S g n d e r - Herred: $3255,54,51,52,53,58,57,59$.

A l s Nørre - Herred: $3261,62,63,64,66$.

Sognene Nr. 3137-3188 d. v. s. Tønder Sønderamt (Nordfrisland): Herrederne Kær, Viding, Bøking, Øerne Sild, For og Amrum ligger nu Syd for Grænsen. Endvidere hører Nr.' 3267-3270, 3272-3473 til Tyskland, medens 3271 B o v Sogn i Vis Herred hører til Danmark og er lagt til Lundtoft Herred: Lundtoft-Vis Herred.

Henvisninger til trykt Litteratur om Sønderjyllands Almuekultur og Folkeminder findes især i Litteraturlisten i Svend Dahls og Axel Linvalds: "Sanderjylland (1919), 323 ff., i H. G r ü n e r . i i l s e n s: Sønderjydske Folkeminder (Fortid og Nutid III 1920, 17 ff.), Traps Danmark IX (1925-29) og Sønderjydske Arbøger 1930, 41 ff. 